\title{
Measurement and Evaluation of Electric Field Strength in Samsun City Center
}

\author{
Çetin Kurnaz *1, Begüm Korunur Engiz ${ }^{2}$
}

Accepted $3^{\text {rd }}$ September 2016

\begin{abstract}
There has been a substantial growth in the use of mobile communication services over the last few years. As a result of this increase in the number of base stations, and electromagnetic (EM) exposure levels have become inevitable. Considering the public debate about possible health hazards caused by electric field strength (E), in this study, evaluating the effect of establishment of $4 \mathrm{G}$ systems on existing E levels is aimed. For this purpose; the total $536 \mathrm{E}$ measurements were conducted in Samsun before and after 1 April 2016. It is seen from the measurements that maximum $\mathrm{E}\left(\mathrm{E}_{\mathrm{max}}\right)$ is $6.32 \mathrm{~V} / \mathrm{m}$ while the maximum average $\mathrm{E}\left(\mathrm{E}_{\mathrm{avg}}\right)$ is $3.26 \mathrm{~V} / \mathrm{m}$ which are both below the limits that are determined by the International Commission on Non-Ionizing Radiation Protection (ICNIRP) and Information and Communication Technologies Authority of Turkey (ICTA). The results demonstrate that the deployment of 4G yielded up to 52.3\% increase in $\mathrm{E}_{\max }$ while $12.5 \%$ in $\mathrm{E}_{\text {avg }}$ values. Furthermore in order to determine the main $\mathrm{E}$ sources band selective $\mathrm{E}$ measurements are conducted and analysed. Analyses demonstrate that $65.6 \%$ of total E is caused by UMTS2100, $22.3 \%$ is produced by GSM900, $4.8 \%$ by GSM1800, $1.3 \%$ by LTE800, and $6 \%$ is generated by devices that use the remaining frequency bands.
\end{abstract}

Keywords: Electric field strength, electromagnetic (EM) radiation, EM measurement, statistical analysis.

\section{Introduction}

Electromagnetic (EM) waves are radiated from many sources, both natural and man-made, that produce electromagnetic pollution. In parallel with technological developments, there has been a dramatic growth in the use of cellular systems (CS) which based on base stations. Because each base station is an electromagnetic radiation (EMR) source, with the increase in the number of base stations, exposed EMR levels have also increased. Since each base station works within a limited geographical region and for limited number of users, mobile system operators must install more base stations in order to meet growing demand for multimedia services, and communicating from any place. There are around 100,000 base stations in Turkey right now, but with the establishment of $4 \mathrm{G}$ systems on 1 April 2016, the estimated number of base stations will be around 130.000 . Because there is a growing number of base stations being placed into crowded places; measuring, evaluating, the levels of EMR and controlling their compliance with standards/limit values has become more crucial than before. Therefore detrimental effects of EMR on human health have been the subject of many researches [1-9] in the last decade.

There are international standards and limits on effects of EMR on human health. The limits are recommended by an international commission ICNIRP which is recognized by World Health Organization (WHO). The limits of electrical field are shown in Table 1 based on ICNIRP and ICTA guidelines on exposure limits [10-11].

The limits are given for exposure averaged over a six minute interval. Each country has its own determined limits. The USA and some European countries use limits determined by the ICNIRP, while other European countries like Switzerland and Italy use 1/10

\footnotetext{
1,2 Department of Electrical and Electronics Engineering, Engineering Faculty, Ondokuz Mayis University, 55139, Samsun/Turkey

* Corresponding Author: Email: ckurnaz@omu.edu.tr

Note: This paper has been presented at the $3^{\text {rd }}$ International Conference on Advanced Technology \& Sciences (ICAT'16) held in Konya (Turkey), September 01-03, 2016.
}

of the ICNIRP's values as a limit. Turkey applies limits that are $75 \%$ of ICNIRP reference levels as endorsed by ICTA [11]. There are currently three mobile communication operators in Turkey and

they use $2 \mathrm{G}$ (second generation), 3G (third generation) and 4G (fourth generation) systems. According to [11], the limits are 30.9 $(\mathrm{V} / \mathrm{m})$ for $900 \mathrm{MHz}$ base station, $43.7(\mathrm{~V} / \mathrm{m})$ for $1800 \mathrm{MHz}$ base station, $45.75(\mathrm{~V} / \mathrm{m})$ for $3 \mathrm{G}$ systems, which is $2100 \mathrm{MHz}$, and also $45.75(\mathrm{~V} / \mathrm{m})$ for $2600 \mathrm{MHz}$ base station.

Table 1. Reference levels for general public exposure to time-varying electric fields for ICNIRP and ICTA

\begin{tabular}{ccc}
\hline \multirow{2}{*}{$\begin{array}{c}\text { Frequency } \\
\text { range (MHz) }\end{array}$} & \multicolumn{2}{c}{ Electric field strength $(\mathbf{V} / \mathbf{m})$} \\
\cline { 2 - 3 } & ICNIRP & ICTA \\
\hline $0.010-0.15$ & 87 & 65.25 \\
\hline $0.15-1$ & 87 & 65.25 \\
\hline $1-10$ & $87 / \mathrm{f}^{1 / 2}$ & $65.25 / \mathrm{f}^{1 / 2}$ \\
\hline $10-400$ & 28 & 21 \\
\hline $400-2000$ & $1.375 \mathrm{f}^{1 / 2}$ & $1.03 \mathrm{f}^{1 / 2}$ \\
\hline $2000-60000$ & 61 & 45.75 \\
\hline & f is frequency in $\mathrm{MHz}$ \\
\hline
\end{tabular}

In this study, to evaluate the effects of newly established $4 \mathrm{G}$ system on electric field strength (E) levels, extensive E measurements were performed before and after 1 April 2016 in Samsun city center in two stage using PMM 8053 and SRM 3006 EMR meter. In the first stage, the changes in EMR levels are investigated at 67 different locations. Then drive test measurements were collected for almost 2 hours and much wider region. Statistical properties of the measured data are determined. The changes in E levels which occurred with the deployment of $4 \mathrm{G}$ systems are visualized through maps. 


\section{Measurement of Electric Field Strength}

In order to determine the changes in $\mathrm{E}$ levels with the deployment of $4 \mathrm{G}$, E measurements were conducted using PMM 8053 EMR meter, in Samsun city center at 67 different locations considering the number of users, line of sight, and distance from a base station. Each measurement location which is separated by a distance of app. 100 meters is shown with red circle in Fig.1.

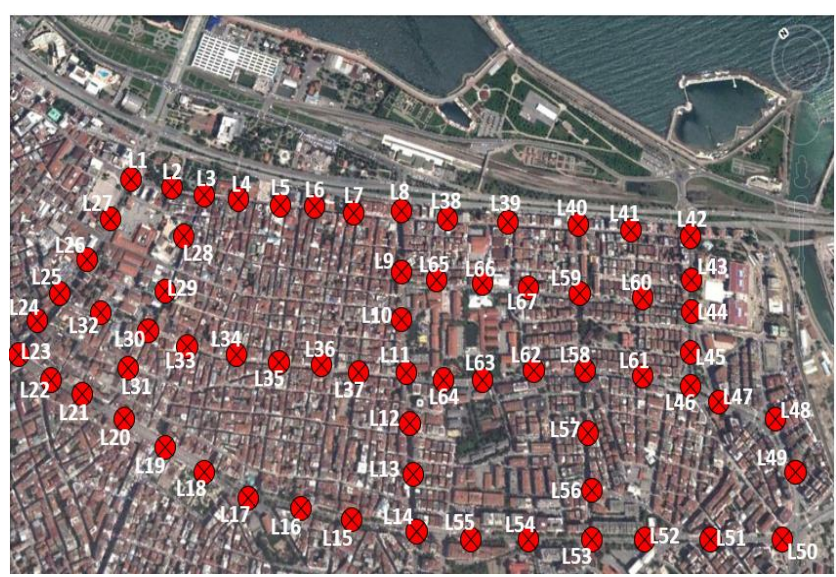

Figure 1. Measurement locations in Samsun city center

Drive test $\mathrm{E}$ measurements were conducted on the route illustrated in Fig. 2 during busy times of evening hours (17.00-19.00) at a speed of $30-50 \mathrm{~km} / \mathrm{h}$.

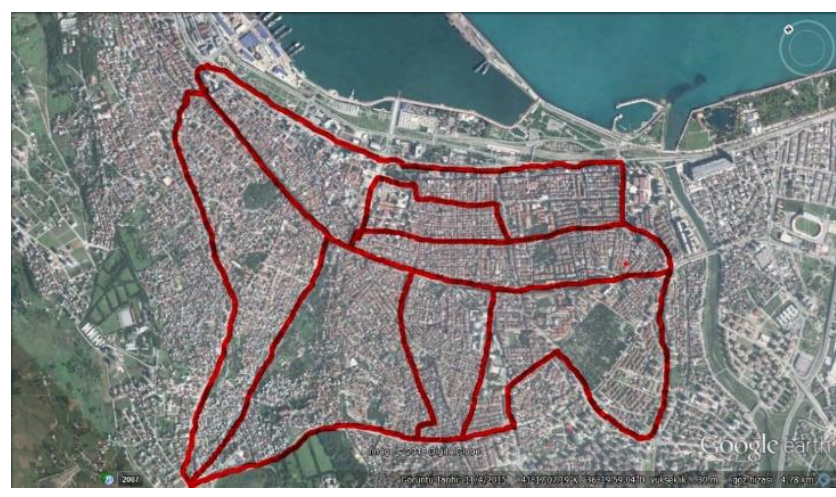

Figure 2. Drive test measurement route

Total $\mathrm{E}$ in the band between $100 \mathrm{kHz}-3 \mathrm{GHz}$ is measured with PMM-8053 with EP-330 isotropic electric field probe [12] twice in March named as M1, M2, and in May 2016, named as M3, and M4 respectively. In each measurement, the maximum electric field strength $\left(E_{\max }\right)$ and average electric field strength $\left(E_{a v g}\right)$ were recorded. Based on the international standards and ordinances released by ICNIRP and ICTA, the duration of each measurement was six minutes. Band selective $\mathrm{E}$ measurements are done with Narda SRM-3006 with 3501/03 isotropic electric field probe [13].

\section{Measurement Results}

In the first stage of the study, the maximum $E\left(E_{\max }\right)$ and the average $\mathrm{E}\left(\mathrm{E}_{\mathrm{avg}}\right)$ which were measured at 67 different locations and are given in Fig. 3a and Fig. 3b respectively. Reasons of various E levels may be: the number of base stations in measurement area, output powers of base stations, distances from the base stations, whether there is line of sight (LOS) between the units or not, and the number of users. As seen from the figure that the $E_{\max }$ is 6.32 $\mathrm{V} / \mathrm{m}$ which is measured at 23th location (measurement time 1). The maximum $\mathrm{E}_{\text {avg }}$ is also obtained at 23th location (measurement time 4) as $3.26 \mathrm{~V} / \mathrm{m}$ accordingly.
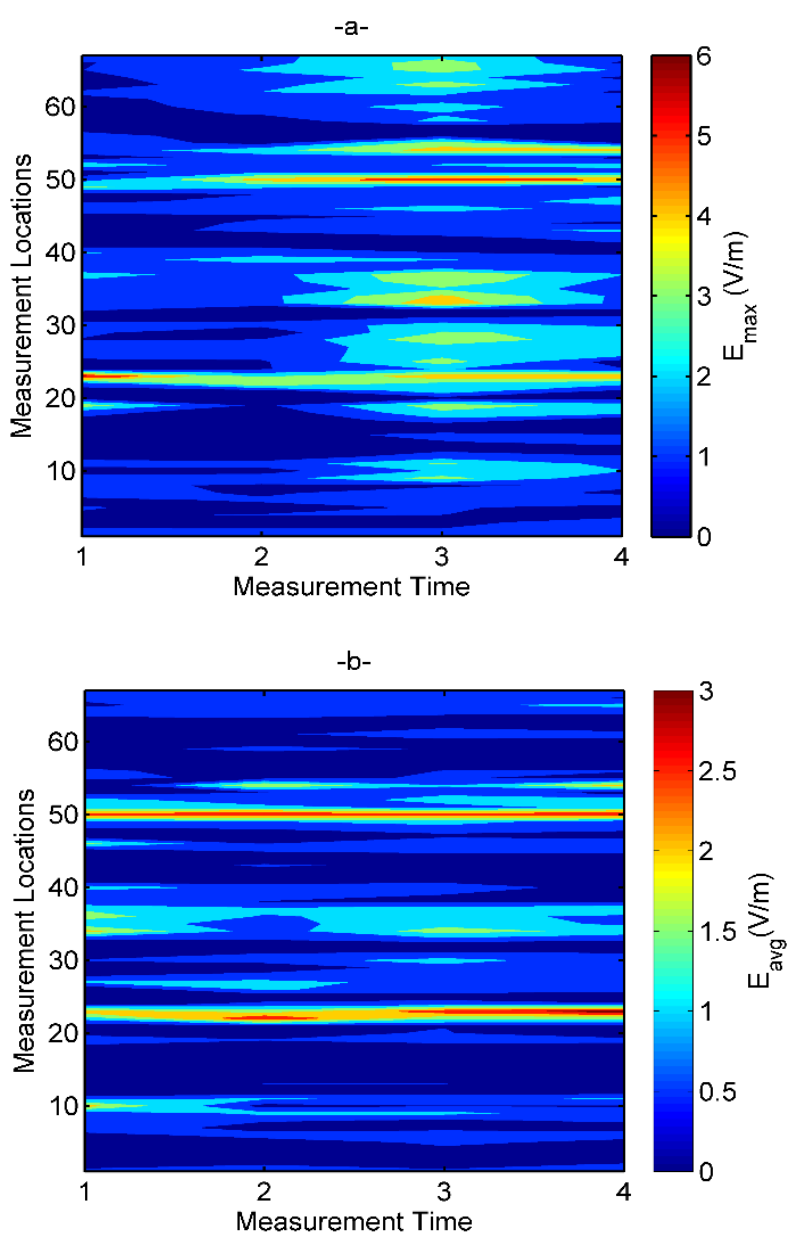

Figure 3. a) Maximum $\left(E_{\max }\right)$ b) Average $\left(E_{a v g}\right)$ Es versus locations

The statistical properties of measured data are determined and listed in Table 2, probability density functions of each measurement are also given in Fig.4. As seen from the Table 2 that $\mathrm{E}_{\max }$ varies from 4.49 to $6.32 \mathrm{~V} / \mathrm{m}$ while $\mathrm{E}_{\text {avg }}$ varies between 2.78 and $3.26 \mathrm{~V} / \mathrm{m}$. Before $4 \mathrm{G}$ the mean of the $\mathrm{E}_{\max }$ is 1.2111 , it increases to 1.8449 after $4 \mathrm{G}$ for the case of Eavg corresponding values are 0.5892 and $0.6628 \mathrm{~V} / \mathrm{m}$. 
Table 2. Statistical properties of the measured data

\begin{tabular}{cccc}
\hline & \multicolumn{3}{c}{$\mathbf{E}_{\max }(\mathbf{V} / \mathbf{m})$} \\
\cline { 2 - 4 } & Max. & Mean & Std. \\
\hline M1 & 6.32 & 1.2001 & 0.9167 \\
\hline M3 & 4.49 & 1.2221 & 0.8349 \\
\hline M4 & 5.59 & 2.1607 & 1.2592 \\
\hline M1 & 5.11 & 1.5291 & 0.9691 \\
\hline M2 & Max. & Mean & Std. \\
\hline M3 & 2.7800 & 0.5718 & 0.6488 \\
\hline M4 & 3.0600 & 0.6066 & 0.6034 \\
\hline & 2.8800 & 0.6940 & 0.5460 \\
\hline & 3.2600 & 0.6316 & 0.6263 \\
\hline
\end{tabular}
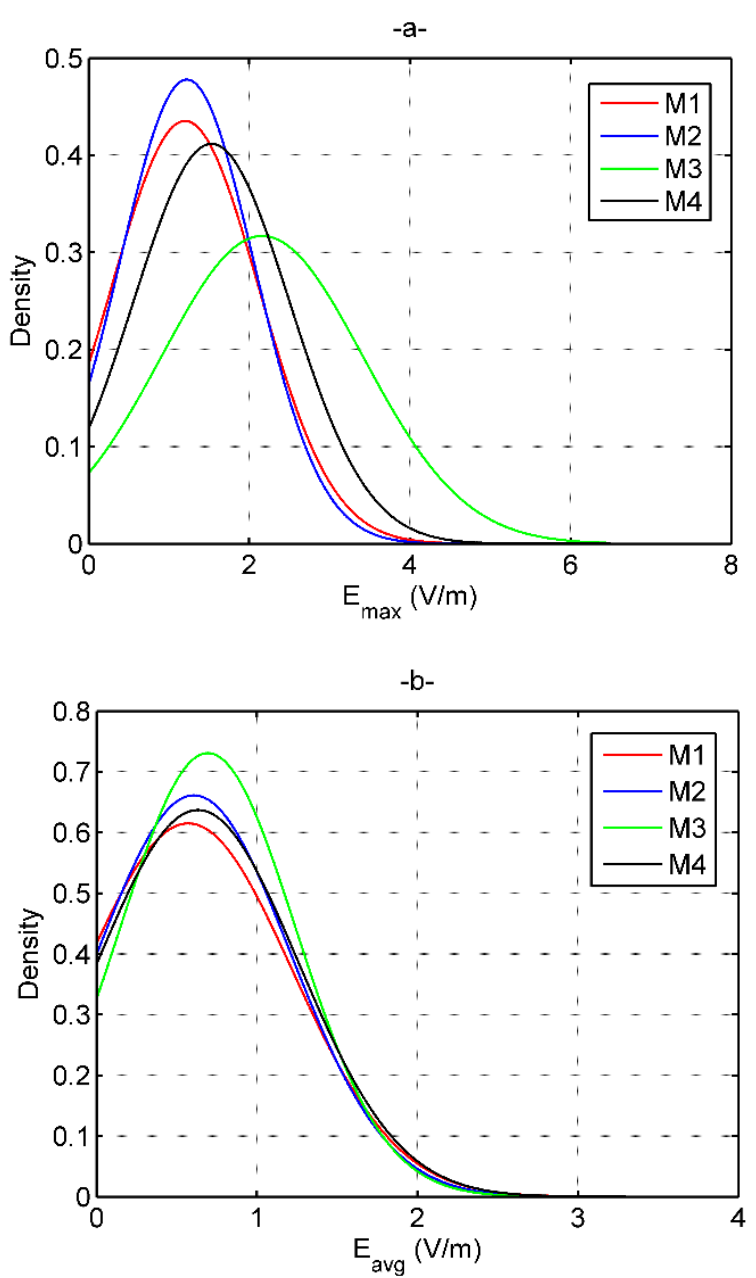

Figure 4. Probability density function for a) $E_{\max }$, b) $E_{a v g}$

In order to have better visualization changes in $\mathrm{E}$ levels are transferred on a map using MapInfo and $\mathrm{E}_{\max } \mathrm{S}$ and $\mathrm{E}_{\mathrm{avg}} \mathrm{S}$ are shown in Fig. 5 and Fig. 6 before and after 4G respectively.

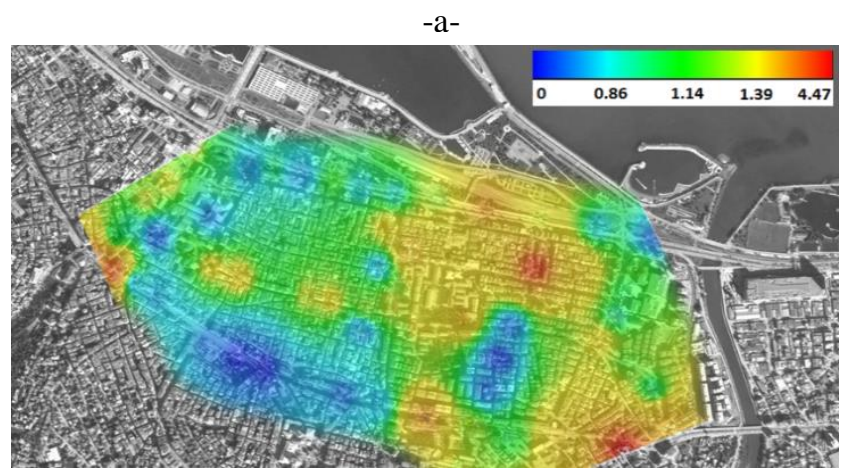

$-b-$

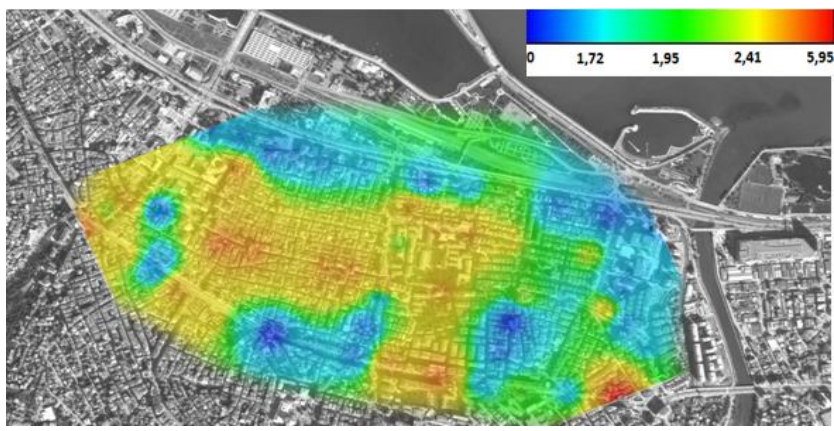

Figure 5. MapInfo picture of $\mathrm{E}_{\max }$ for a) before $\mathrm{b}$ ) after $4 \mathrm{G}$

$-\mathrm{a}-$

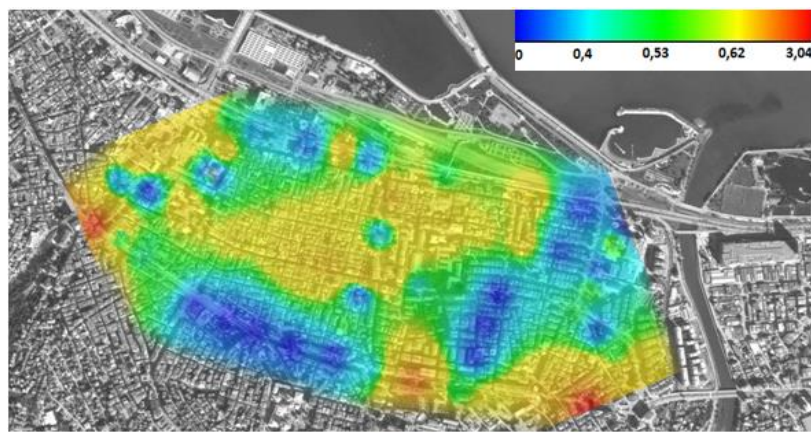

$-b-$

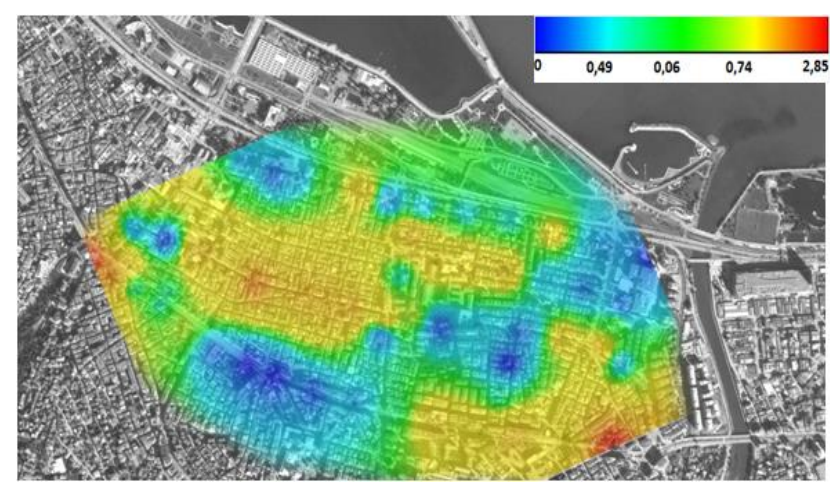

Figure 6. MapInfo picture of $E_{\text {avg }}$ for a) before $b$ ) after $4 \mathrm{G}$ 
In the second stage of the study, band selective E measurements were done using SRM-3006 and through drive test. Examples of frequency spectrum at any measurement locations are illustrated in Fig. 7 for the measurement performed before and after 4G.

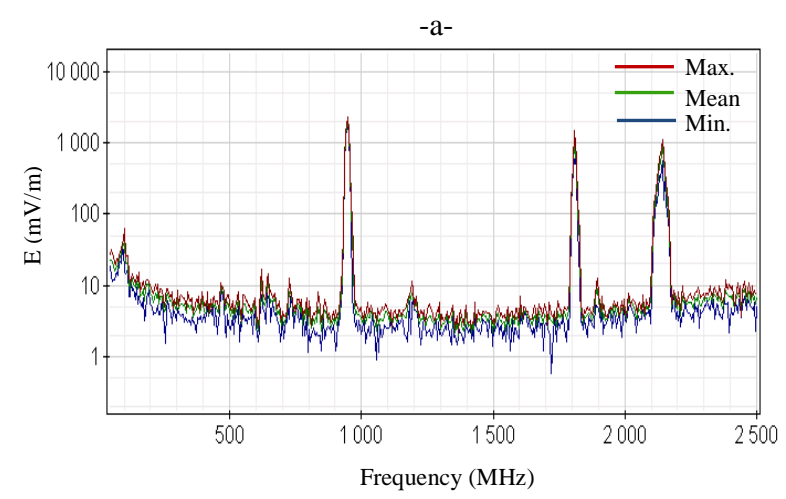

$-b-$

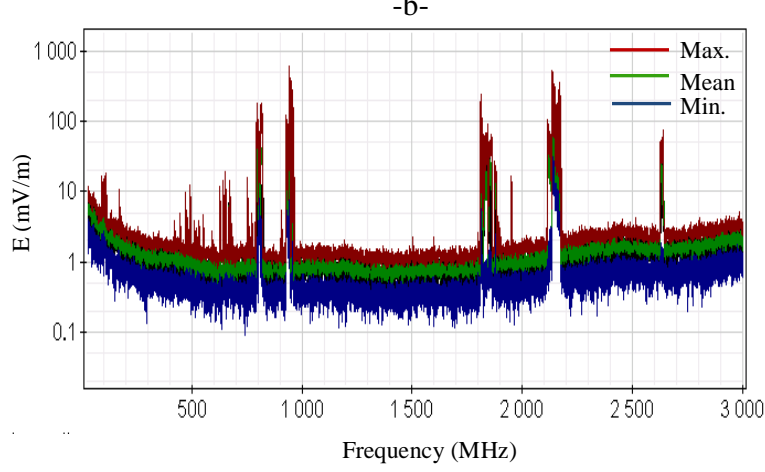

Figure 7. An example of frequency spectrum a)before, b)after establishment of $4 \mathrm{G}$

The details of SRM-3006 measurements, which contain the E sources (service name, frequency ranges etc.) as illustrated in Table 3 for both measurements. In the Table, each E source has a specific index number and the $19^{\text {th }}$ index represents $E$ levels within undefined frequency bands, and the $20^{\text {th }}$ index presents total $\mathrm{E}\left(\mathrm{E}_{\mathrm{T}}\right)$ values of the medium.

It is seen from Table 3 that main sources of E are GSM900, GSM1800 and UMTS2100 bands for before 4G while LTE800, GSM900, GSM1800 and UMTS2100 bands for after 4G. When total $\mathrm{E}$ is $1.530 \mathrm{~V} / \mathrm{m}, 0.576 \mathrm{~V} / \mathrm{m}$ of this value is arise from GSM900 while $0.345 \mathrm{~V} / \mathrm{m}$ and $1.369 \mathrm{~V} / \mathrm{m}$ are from GSM1800 and UMTS2100 respectively. The total E of medium is calculated as follows:

$$
\mathrm{E}_{\mathrm{T}}=\sqrt{\sum_{\mathrm{i}=1}^{19}\left(\mathrm{E}_{\mathrm{i}}\right)^{2}}
$$

where $E_{i}$ is the electric field for $i^{\text {th }}$ band. $E_{19}$ is the electric field caused by the other transmitters excluding 18 bands. The contribution percentage $\left(\mathrm{P}_{\mathrm{i}}\right)$ of each band is calculated as in Eq. (2).

$$
P_{i}=\frac{E_{i}^{2}}{E_{T}^{2}} \times 100
$$

The pie chart showing the distributions of all E sources is given in Fig. 8 for before and after 4G. As seen from Fig. 8.a, 99.4\% of total $\mathrm{E}$ in the medium is emitted by base stations which use $900 \mathrm{MHz}$
(GSM900), 1800MHz (GSM1800) and 2100MHz (UMTS2100) frequency bands. Among the four of them, UMTS has the most contribution with $80.1 \%$. It can be clearly seen from Fig. $8 \mathrm{~b}$ that establishment of $4 \mathrm{G}$ causes a considerably increase in contribution of LTE band.

\begin{tabular}{|c|c|c|c|c|c|}
\hline \multirow{2}{*}{ Index } & \multirow{2}{*}{$\begin{array}{c}\text { Service } \\
\text { Name }\end{array}$} & \multirow{2}{*}{$\begin{array}{c}\text { Lower } \\
\text { Frequency }\end{array}$} & \multirow{2}{*}{$\begin{array}{c}\text { Upper } \\
\text { Frequency }\end{array}$} & \multicolumn{2}{|c|}{$\mathbf{E}(\mathbf{V} / \mathbf{m})$} \\
\hline & & & & Before & After \\
\hline 1 & Low Band & $30 \mathrm{MHz}$ & $87.4 \mathrm{MHz}$ & 0.043 & 0.049 \\
\hline 2 & FM Band & $87.5 \mathrm{MHz}$ & $108 \mathrm{MHz}$ & 0.022 & 0.055 \\
\hline 3 & Air Band & $108.1 \mathrm{MHz}$ & $136 \mathrm{MHz}$ & 0.018 & 0.018 \\
\hline 4 & Land Band-I & $136.1 \mathrm{MHz}$ & $173 \mathrm{MHz}$ & 0.022 & 0.017 \\
\hline 5 & TV VHF Band & $173.1 \mathrm{MHz}$ & $230 \mathrm{MHz}$ & 0.017 & 0.016 \\
\hline 6 & Land Band-II & $230.1 \mathrm{MHz}$ & $400 \mathrm{MHz}$ & 0.023 & 0.022 \\
\hline 7 & Land Band-III & $400.1 \mathrm{MHz}$ & $470 \mathrm{MHz}$ & 0.014 & 0.013 \\
\hline 8 & TV UHF Band & $470.1 \mathrm{MHz}$ & $800 \mathrm{MHz}$ & 0.070 & 0.068 \\
\hline 9 & LTE800 & $800.1 \mathrm{MHz}$ & $860 \mathrm{MHz}$ & 0.000 & 0.189 \\
\hline 10 & ETC1 & $861.1 \mathrm{MHz}$ & $889.9 \mathrm{MHz}$ & 0.005 & 0.006 \\
\hline 11 & GSM900 & $890 \mathrm{MHz}$ & $960 \mathrm{MHz}$ & 0.576 & 0.787 \\
\hline 12 & ETC2 & $960.1 \mathrm{MHz}$ & $1.7 \mathrm{GHz}$ & 0.040 & 0.090 \\
\hline 13 & GSM1800 & $1.701 \mathrm{GHZ}$ & $1.88 \mathrm{GHz}$ & 0.345 & 0.365 \\
\hline 14 & DECT & $1.881 \mathrm{GHz}$ & $1.899 \mathrm{GHz}$ & 0.005 & 0.005 \\
\hline 15 & UMTS2100 & $1.9 \mathrm{GHz}$ & $2.17 \mathrm{GHz}$ & 1.369 & 1.350 \\
\hline 16 & ETC4 & $2.171 \mathrm{GHz}$ & $2.399 \mathrm{GHz}$ & 0.032 & 0.126 \\
\hline 17 & WLAN & $2.400 \mathrm{GHz}$ & $2.483 \mathrm{GHz}$ & 0.022 & 0.023 \\
\hline 18 & ETC5 & $2.484 \mathrm{GHz}$ & $3.000 \mathrm{GHz}$ & 0.059 & 0.108 \\
\hline 19 & Residual services & & & 0.029 & 0.223 \\
\hline 20 & Total & & & 1.530 & 1.666 \\
\hline
\end{tabular}

Table 3. Frequency selective E values
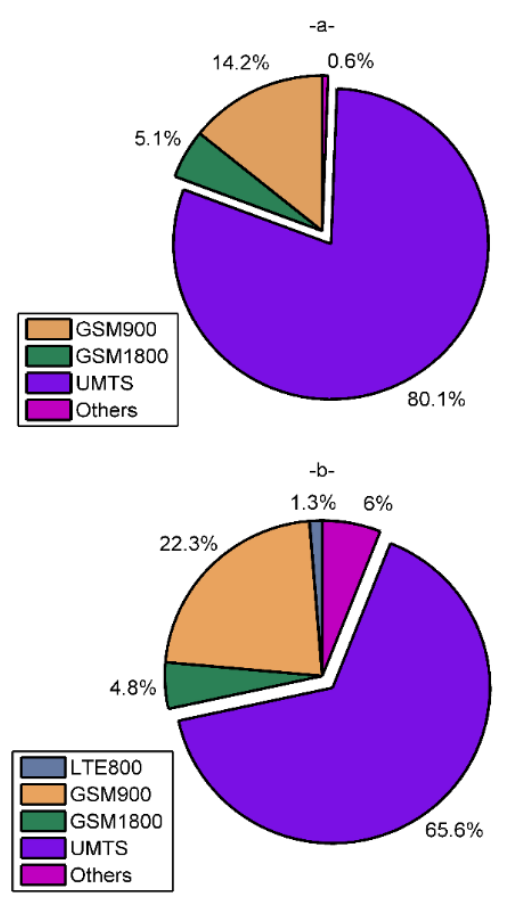

Figure 8. Pie chart of $\mathrm{E}$ a) before, b)after $4 \mathrm{G}$ 
On the defined drive test route the changes in E field strengths were recorded before 1 April 2016 and shown in Fig.9 for GSM900, GSM1800 and UMTS2100 which consist $99.4 \%$ of total E. The statistical properties of total $\mathrm{E}$ obtained through drive test are as following. The maximum, the mean value and standard deviation of total $\mathrm{E}$ are $3.729 \mathrm{~V} / \mathrm{m}, 0.9772 \mathrm{~V} / \mathrm{m}$ and $0.7615 \mathrm{~V} / \mathrm{m}$ respectively.

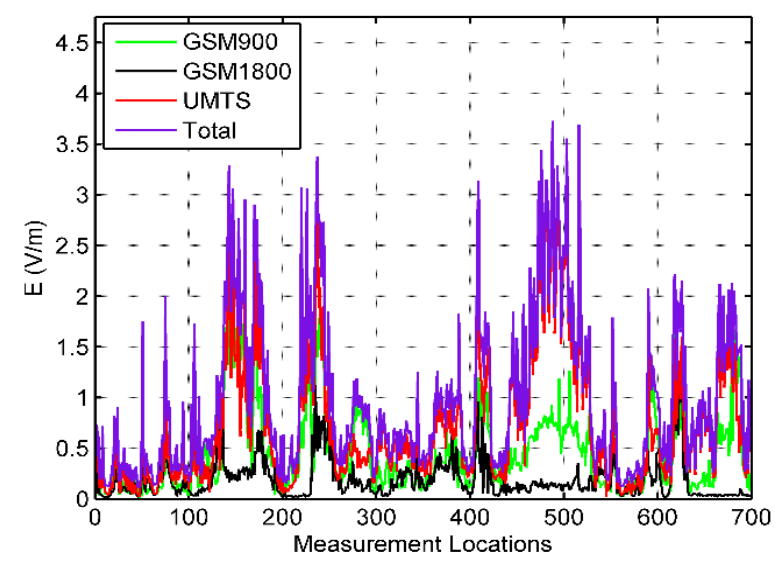

Figure 9. Band selective E measurements

The histograms of three main $\mathrm{E}$ sources and total $\mathrm{E}$ are shown in Fig. 10 while general properties are summarized in Table 4 . It can be concluded both from Fig. 10 and Table 4 that at 241 locations total $\mathrm{E}$ value higher than $1 \mathrm{~V} / \mathrm{m}$, while only at 16 locations total $\mathrm{E}$ is above $3 \mathrm{~V} / \mathrm{m}$.

Table 4. Assessment of main E sources and total E

\begin{tabular}{lccc}
\hline & $>\mathbf{1 ~ V / m}$ & $>\mathbf{2 ~ V} / \mathbf{m}$ & $>\mathbf{3 ~ V} / \mathbf{m}$ \\
\hline GSM900 & 74 & 1 & 0 \\
\hline GSM1800 & 6 & 0 & 0 \\
\hline UMTS & 186 & 48 & 10 \\
\hline Total & 241 & 83 & 16 \\
\hline
\end{tabular}

In order to determine statistical relationships between main $\mathrm{E}$ sources and total E, correlation coefficients are calculated and listed in Table 5. As seen from the Table the maximum correlation is equal to 0.9624 between UMTS and Total E, which is very high.

Table 5. Correlation coefficients between main E sources and total E

\begin{tabular}{ccccc}
\hline & GSM900 & GSM1800 & UMTS & Total \\
\hline GSM900 & 1 & 0.3580 & 0.6101 & 0.7839 \\
\hline GSM1800 & 0.3580 & 1 & 0.2469 & 0.3670 \\
\hline UMTS & 0.6101 & 0.2469 & 1 & $\mathbf{0 . 9 6 2 4}$ \\
\hline Total & 0.7839 & 0.3670 & $\mathbf{0 . 9 6 2 4}$ & 1 \\
\hline
\end{tabular}
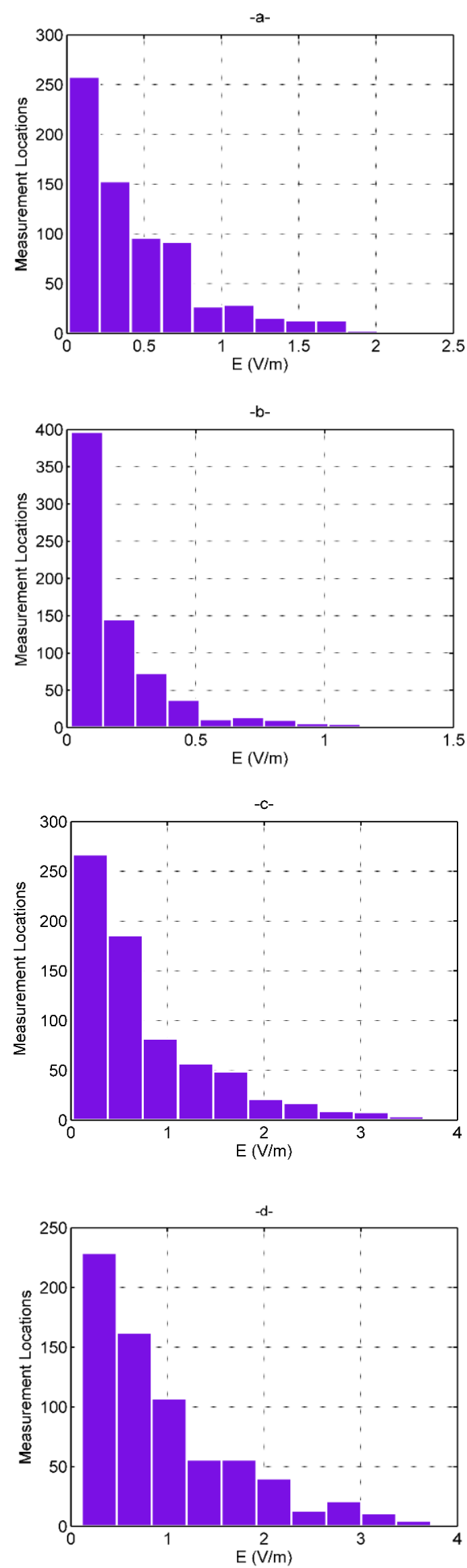

Figure 10. Histograms of a)GSM900, b)GSM1800, c)UMTS, d)Total E for drive test measurement 


\section{Conclusion}

In this study, in order to determine the effect of deployment of $4 \mathrm{G}$ systems on E levels, extensive measurements were performed at 67 different locations in Samsun city centre before and after 4G. According to 536 measurements the maximum total electric field strength $\left(E_{\max }\right)$ is $6.32 \mathrm{~V} / \mathrm{m}$ while the maximum average electric field strength $\left(\mathrm{E}_{\mathrm{avg}}\right)$ is $3.26 \mathrm{~V} / \mathrm{m}$. The results demonstrate that the deployment of $4 \mathrm{G}$ yielded up to $52.3 \%$ increase in $\mathrm{E}_{\max }$ while $12.5 \%$ in Eavg values. Even though the measured E levels are below the limits; there is a significant increase in them in parallel with 4G. Furthermore, band selective measurements were conducted to determine the distributions of the main $\mathrm{E}$ sources in total $\mathrm{E}$. A detailed examination of band selective measurements demonstrate that the main E sources in Samsun city center are the base stations which use $800 \mathrm{MHz}, 900 \mathrm{MHz}, 1800 \mathrm{MHz}$ and $2100 \mathrm{MHz}$ frequency bands, and $2100 \mathrm{MHz}$ has the most contribution to total $\mathrm{E}$ with $65.6 \%$.

\section{References}

[1] Kurnaz Ç., "An Emprical Modelling of Electromagnetic Pollution on an University Campus", The Applied Computational Electromagnetic Society Express Journal, vol.1, no.2, pp.76-79, 2016.

[2] Gül B. K, Kurnaz Ç., and Engiz B. K, "Measurement and Evaluation of Electromagnetic Pollution in Ondokuz Mayıs University Kurupelit Campus in Samsun, Turkey", Third International Conference on Advances in Information Processing and Communication Technology, pp.80-84, Rome, Italy, 2015.

[3] Mousa A., "Electromagnetic radiation measurements and safety issues same cellular base stations in Nablus", Journal of Engineering Science and Technology Review, vol. 4, no. 1, pp. 35-42, 2011.

[4] Genç O., Bayrak M., and Yaldız E., "Analysis of the effects of GSM bands to the electromagnetic pollution in the RF spectrum", Progress in Electromagnetics Research, vol.101, pp.17-32, 2010.

[5] Miclaus S., and Bechet P., "Estimated and Measured values of the Radiofrequency Radiation Power Density around Cellular Base Stations", Environment Physics, vol. 52, no. 3-4, pp. 429-440, 2007.

[6] Seyfi L., "Measurement of electromagnetic radiation with respect to the hours and days of a week at $100 \mathrm{kHz}-3 \mathrm{GHz}$ frequency band in a Turkish dwelling", Measurement, vol.46, no.9, pp.3002-3009, 2013.

[7] Baltrenas P., and Buckus R., "Measurements and analysis of the electromagnetic fields of mobile communication antennas", Measurement, vol.46, no.10, pp.3942-3949, 2013.

[8] Koprivica M., Slavkovic V., Neskovic N., Neskovic A., "Statistical Analysis of Electromagnetic Radiation Measurements in the Vicinity of GSM/UMTS Base Station Installed on Buildings in Serbia", Radiation Protection Dosimetry, pp.1-14, 2015, doi: 10.1093/rpd/ncv372.

[9] Karadag T, Yüceer M., and Abbasov T., "A Large-Scale Measurement, Analysis And Modelling of Electromagnetic Radiation Levels in the Vicinity of GSM/UMTS Base Stations in an Urban Area", Radiation Protection Dosimetry (2015), pp. 1-14, doi:10.1093/rpd/ncv008.
[10] ICNIRP Guidelines, "Guidelines for Limiting Exposure to Time-Varying Electric, Magnetic, and Electromagnetic Fields (up to $300 \mathrm{GHz}$ )", International Commission on NonIonizing Radiation Protection, Health Physics vol.74, no.4, pp.494-522, 1998.

[11] Information and Communication Technologies Authority of Turkey, "Ordinance change on By-Law on Determination, Control and Inspection of the Limit Values of Electromagnetic Field Force from The Electronic Communication Devices According to International Standards", Law no.29497, 9 October 2015.

[12] www.pmm.it/docs/8053en1001.pdf

[13] www.narda-sts.us/pdf_files/DataSheets/SRM3006_DataSheet.pdf 